\title{
POTENTIAL OF THERMAL EMISSIVITY FOR MAPPING OF GREENSTONE ROCKS AND ASSOCIATED GRANITOIDS OF HUTTI MASKI SCHIST BELT , KARNATAKA
}

\author{
ARINDAM GUHA, K VINOD KUMAR \\ GEOSCIENCES GROUP , NATIONAL REMOTE SENSING CENTRE, INDIAN SPACE RESEARCH \\ ORGANISATION, BALANAGAR, HYDERABAD(arindam_g,vinodkumar_k)@nrsc.gov.in
}

ISPRS Technical Commission VIII Mid Term Symposium 2014

Key Words: Alpha Residual, Decorrelation stretching, Emissivity, Emissivity normalisation, granite, granodiorite, Reference Channel, Minimum Noise Fraction, Thermal data

\begin{abstract}
:
In the present study, different temperature-emissivity separation algorithms were used to derive emissivity images based on processing of ASTER( Advanced spaceborne thermal emission and reflection radiometer) thermal bands. These emissivity images have been compared with each other in terms of geological information for mapping of major rock types in Hutti Maski schist Belt and its associated granitoids. Thermal emissivity images are analyzed conjugately with thermal radiance image, radiant temperature image and albedo image of ASTER bands to understand the potential of thermal emissivity in delineating different rock types of Archaean Greenstone belt. The emissivity images derived using different emissivity extraction algorithms are characterised with poor data dimensionality and signal to noise ratio. Therefore, Inverse MNF false-colour composites(FCC) are derived using bands having better signal to noise(SNR)ratio to enhance the contrast in emissivity. It has been observed that inverse-MNF of emissivity image; which is derived using emissivity-normalisation method is suitable for delineating silica variations in granite and granodioritic gneiss in comparison to other inverse- MNF-emissivity composites derived using other emissivity extraction algorithms(reference channel and alpha residual method). Based on the analysis of ASTER derived emissivity spectra of each rocks, band ratios are derived(band 14/12,band 10/12) and these ratios are used to delineate the rock types based on index based FCC image. This FCC image can be used to delineate granitoids with different silica content. The geological information derived based on processing of ASTER thermal images are further compared with the image analysis products derived using ASTER visible-near-infrared(VNIR) and shortwave infrared(SWIR) bands. It has been observed that delineation of different mafic rocks or greenstone rocks(i.e. separation between chlorite schist and metabasalt) are better in SWIR composites and these composites also provide comparable results with thermal bands in terms of delineation of different types of granitoids.
\end{abstract}

\section{INTRODUCTION}

The emissivity of an isothermal, homogeneous emitter is defined as the ratio of the actual emitted radiance to the radiance emitted from a black body at the same thermodynamic temperature(Norman, 1995). It is an important geophysical parameter of terrain elements for the studies related to climatology, hydrology and also used in modelling of the greenhouse effect (Hulley, 2009).

Derivation of emissivity information from multichannel ASTER (Advanced Spaceborne Thermal Emission and Reflection Radiometer) data and using them for mapping of geological units of Precambrian rocks is an important aspect of research. Long wave or thermal emission is the response of atomic processes operated within the atomic structures of terrain elements in response to absorption of incident electromagnetic radiation of specific band width. Therefore, emissivity can be used to study the atomic structures of minerals and it is specially found suitable for identification of different silicate minerals. Emissivity can be used to identify individual minerals, and has been also related to silica content of rocks (Lyon 1972). Therefore, surface emissivity has been regarded as the one of promising geophysical parameter for mapping rock types with varying silica $\left(\mathrm{SiO}_{2}\right)$ content. Major silicate minerals constitute the earth crust such as quartz and feldspars are not characterised with pronounced spectral features in the shortwave infrared(SWIR) region(bandwidth is restricted within the wavelength domain of 1 micrometer to 2.5 micrometer), rather these minerals can be targeted based on their emissivity features. Importantly, igneous rocks are characterised with varying silica( i.e. silicon-di-oxide) content. Therefore spectral delineation of different igneous rocks having varying silica content can be attempted using emissivity features based on processing of multiband thermal sensor data like ASTER. In this regard, emissivity signatures have the potential in delineating green schist rocks surrounded with granitoids of varying silica content.

In the early days of geological studies using remote sensing data, single TIR(Thermal Infrared) band of Landsat Thematic mapper(TM) has been used to differentiate different geological units using radiant temperature image. The differences in thermal properties( based on derivation of thermal inertia and also variation in temperature) have also been used to identify geological units(Abrams et al., 1984; Kahle and Rowan, 1980; Lyon, 1972).For example, important igneous rocks like basalt, gabbro, granites etc are delineated from the apparent thermal inertia images (ATI). Further properties of surface cover or soil cover resulted due to variations in moisture can also be delineated in thermal inertia images. However, thermal inertia characterisation requires day and night images of same area with a small time difference, which restricts its usefulness. On the other hand, multiband thermal sensor like ASTER can be used to derive emissivity of terrain elements in each band and provide information on variation in emissivity of terrain elements across the wavelength domain from 8-12 micrometer and this parameter can be used for compositional mapping. In recent times different thermal composites and thermal ratio images have been used to delineate rock types (Kalinowski and 
Oliver, 2004; Ninomiya et al., 2005). It is well known now that quartz-rich felsic rocks such as granite, dry river sand appear reddish in the L1B daytime false colour composite image derived using different thermal bands of ASTER sensor. This is due to the fact that the spectral emissivity of quartz is lower in the $8-9 \mu \mathrm{m}$ region (bands 10 to 12 ) than in the $10-12 \mu \mathrm{m}$ region(band 13 and 14). Feldspar also has absorption in band 11. But mafic rocks appear colourless in this composite image as they have higher spectral emissivities in 8-9 $\mu \mathrm{m}$ region(Yajima et al. ). Based on an analysis of TIR spectral characteristics of rocks, Yoshiki Ninomiya has proposed several spectral indices for the mapping of quartzose, carbonate, and mafic rocks using ASTER data. Many important geological units were also mapped in the thermal images based on emissivity(Bertoldi et al., 2011; Ding et al.; Matar and Bamousa, 2013; Ninomiya et al., 2005; Ninomiya et al., 1997; Rowan et al., 2005).

But characterisation of emissivity and its variation in different thermal bands of ASTER data are essential to understand the practical potential of emissivity data in mapping different rock types specially the rocks exposed under the influence of intense tropical weathering set up of India. Thermal infrared at-surface radiance is recorded by thermal bands of ASTER sensor is a function of both the temperature and emissivity of the surface. Both of these parameters known for very small variance among the geologic materials exposed on the earth's surface(Yajima and Yamaguchi, 2013). This results a high degree of correlation between TIR channels for emissivity and radiant temperature values. Therefore, image processing algorithms which are used to enhance the spectral contrast in thermal bands such as decorrelation stretch (DCS) etc. (displays emissivity variations and corresponding mineralogical variations in terms of variations in colour in the emissivity composites) have been regarded as important tools for ASTER thermal data for lithological mapping(Gillespie, 1992).

In the present study, attempt has been made to utilise suitable image analysis methods for processing of ASTER derived emissivity bands independently and also in conjunction with albedo and radiant temperature images to extract geological information on rock types essential for spatial mapping. In order to understand, standalone geological information content of thermal bands, attempt has been made to compare the results of interpretation of processed emissivity products with the results obtained from the analysis of ASTER VNIRSWIR(visible-near infrared, short wave infrared) data in terms of delineation of major rock types of Hutti-Maski Schist Belt. The work also has the relevance in present context as record of mapping different geological units of green schist rocks and associated granitoids based on contrasting emissivity parameters derived from different emissivity extraction algorithms and comparison of the results of such analysis are limited in the literature.

\section{STUDY AREA AND GENERAL GEOLOGY}

Study area is situated at the western part of Raichur district of Karnataka State; which is located at south western part of India. The study area is restricted within the latitude from $16^{0} 1^{\prime}$ to $16^{\circ} 16^{\prime}$ and the longitude from $76^{\circ} 35^{\prime}$ to $76^{0} 37^{\prime}$ (Fig.1). Geologically, study area is characterised with greenstone rocks of green schist and amphibolite facies, exposed with hookshaped outcrop pattern(Curtis and RadhaKrishna, 1995). Exposures of amphibolite/metabasalts were hardly preserved at surface with appreciable spatial extent. In general, these rocks have been deeply weathered and in-situ soil is developed. In the study area, metabasalt and amphibolites are main rocks representing the greenstone rocks. Amphibolite has dark green colour and at places, it is schistose. Amphibolite exposures are seen at the north-eastern part of the hook of Hutti schist belt. Metabasalt is dominant component of greenstone rock. It is fine grained and characterised with profused development of pillows but blanketed with black soil on surface.

In addition to above components of greenstone rocks, amphibolites are also admixed with gneiss known as mixites in few places (e.g. Palkanmardi mixites)(Curtis and RadhaKrishna, 1995). Black soil often blanket metabasalts; which are chlortic in terms of mineralogy. Black soil is developed from metabasalt underneath the climate which is humid with erratic drought sequence(Roy and Barde, 1962).Greenstone rocks are closely associated with intrusive granitic plutons exposed along the margin of the belt(Fig.2). The contact zone of these granites with granodiorites are important for gold mineralisation specially around remobilised portion of the contact. The grey granitoid is older phase and has recognisable gneissosity locally known as Kavital granitoid and it is granodioritic in composition. This granite outcrops at south east and north east part of the schist belt. The younger phase of granite is exposed at the northern part of the study area and is orthoclase feldspar rich and pink in colour. Locally this granite is known as Yelgatti Granite. Younger granite has intruded older Kavital granites at several place at eastern part of the study area (Fig.3). Exposures of migmatites or granodiortic peninsular gneiss are restricted to the western side of the study area.((Fig.3).Acid rocks of granophyres, felsic porphyry etc. also occur within the schist belt and found to have intruded both green schist and granitoid rocks and identified near Chinchergi area(Curtis and RadhaKrishna, 1995). It addition to above, several granite and pegmatoid veins have intruded the greenstone rocks and these intrusion is associated with the later phase of deformation (associated with second stage of regional deformation).In this regard, it is worthwhile to mention that Hutti-Maski schist belt has undergone three distinct phase of regional deformation. Second phase of deformation is pronounced with NNW trend and contributed in the formation of shear zone in the study area(Roy, 1979).Field-photographs of surface exposures of different rock types and soil cover is shown in Fig.2.
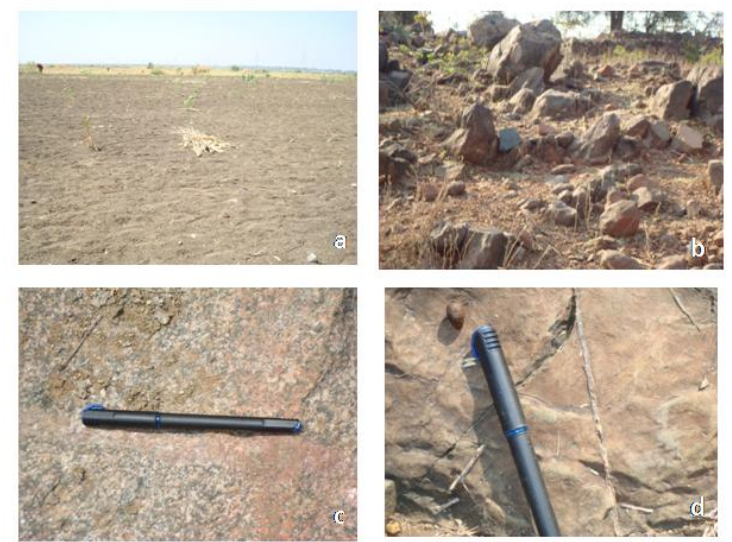

Figure 2 a. Black soil developed over metabasalt. b Exposures of amphibolite. c. Younger K- Feldspar rich pink granite(locally known asYelgatti Granite). d. Older Granodiorite(locally known as Kavital Granite) 


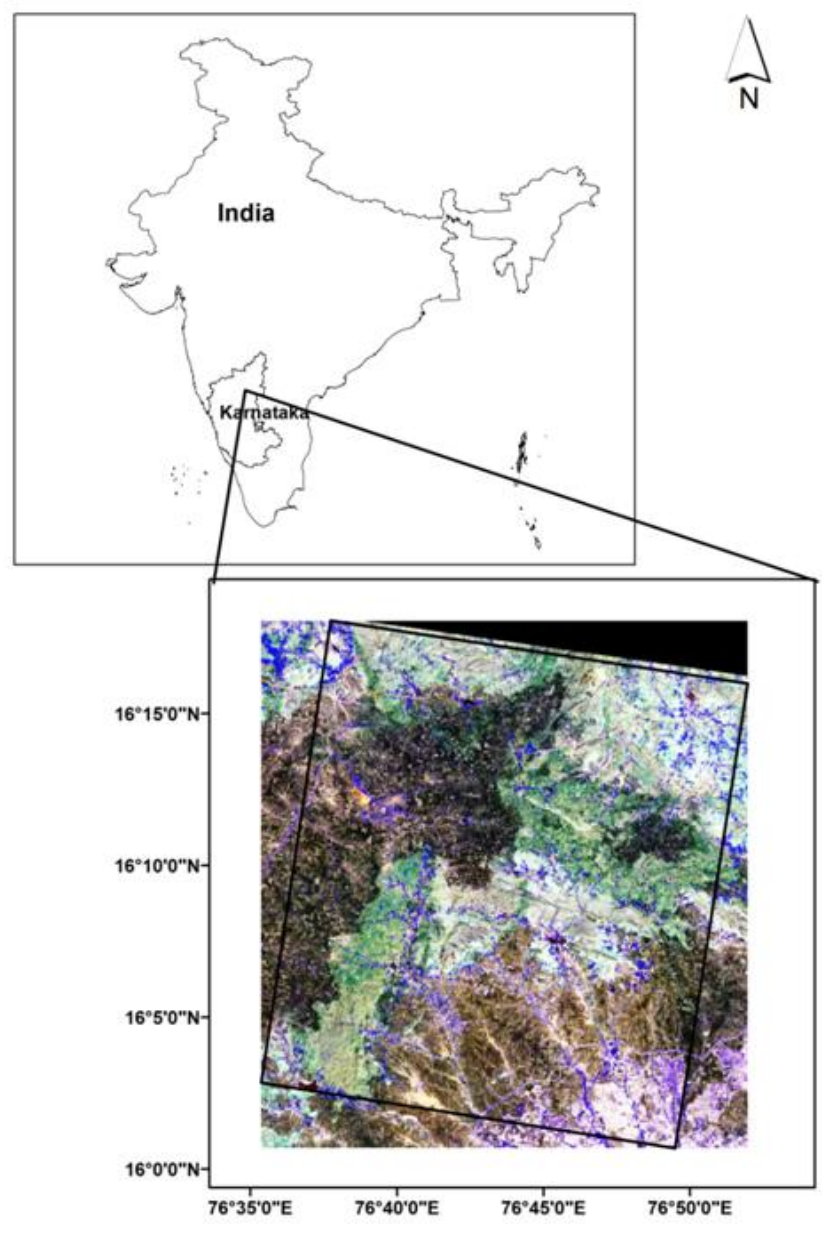

Figure 1: Study area

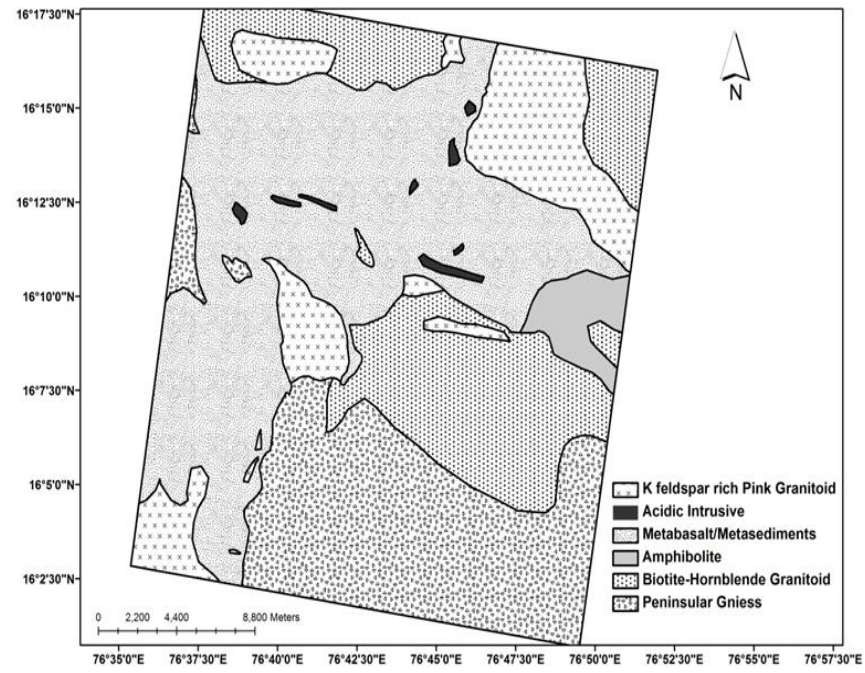

Figure 3: Geological Map of the study area(prepared from consulting District Resource Map of Raichur District and Koppal District, Karnataka prepared by Geological Survey of India in 1:250000 scale and Geological Map of Hutti Maski Schist Belt prepared by Sundaram et al. 1:150000. The map is further modified based on image analysis supplemented with field survey along selected traverses )

\section{METHODOLOGY}

We have processed Level 1B "at sensor" radiance data of thermal bands of ASTER sensor. ASTER TIR bands are conjugately used with ASTER VNIR SWIR bands to analyse the potential of thermal bands of ASTER data and compare the results of the thermal data analysis with the results obtained from VNIR-SWIR bands. The detail specification ASTER sensor operative within the broad spectral domain encompassing visible-near infrared(VNIR), shortwave infrared(SWIR) and thermal infrared(TIR) electromagnetic domain have been illustrated in table 1. ASTER sensor is onboard in EO 1 satellite platform of NASA(National Aeronautics and Space Administration, America) of America have been operative since 1999 and have been widely used for geological applications(Abrams, 2000).

ASTER VNIR-SWIR data used for deriving albedo image and also deriving ratio images to delineate different rock types(Yajima and Yamaguchi, 2013). ASTER VNIR and SWIR bands are independently calibrated using image based vicarious calibration methods to derive relative reflectance. ASTER VNIR bands are calibrated using "Internal average relative reflectance(IARR)" method and SWIR bands are calibrated using $\log$ residual method. Details of these methods and its potential in deriving relative reflectance image suitable for geological analysis have been discussed in literature(Guha, et al.2013).

\begin{tabular}{|c|l|c|c|c|}
\hline $\begin{array}{c}\text { Subsyst } \\
\text { ems }\end{array}$ & $\begin{array}{c}\text { Band } \\
\text { Numb } \\
\text { ers }\end{array}$ & $\begin{array}{c}\text { Spectral } \\
\text { domain(Micromete } \\
\text { r) }\end{array}$ & $\begin{array}{l}\text { Spatial } \\
\text { Resoluti } \\
\text { on }\end{array}$ & $\begin{array}{l}\text { Radiome } \\
\text { tric } \\
\text { Resoluti } \\
\text { on }\end{array}$ \\
\hline VNIR & 1 & $52-0.60$ & 15 & 8 bits \\
\hline & 2 & $63-0.69$ & 15 & 8 bits \\
\hline & 3 & $78-0.86$ & 15 & 8 bits \\
\hline & $3 \mathrm{~B}$ & $78-0.86$ & 15 & 8 bits \\
\hline SWIR & 4 & $1.60-1.70$ & 30 & 8 bits \\
\hline & 5 & $2.145-2.185$ & 30 & 8 bits \\
\hline & 6 & $2.185-2.225$ & 30 & 8 bits \\
\hline & 7 & $2.235-2.285$ & 30 & 8 bits \\
\hline & 8 & $2.965-2.360$ & 30 & 8 bits \\
\hline & 9 & $2.360-2430$ & 30 & 8 bits \\
\hline TIR & 10 & $8.125-8.475$ & 90 & 12 bits \\
\hline & 11 & $8.8475-8.825$ & 90 & 12 bits \\
\hline & 12 & $8.925-9.275$ & 90 & 12 bits \\
\hline & 13 & $10.25-10.95$ & 90 & 12 bits \\
\hline & 14 & $10.95-11.65$ & 90 & 12 bits \\
\hline
\end{tabular}

Table 1:Specification of ASTER data

ASTER VNIR-SWIR bands are used to derive false colour composites(FCC) and also used to derive few false colour band ratio composites using selected bands for delineating lithology. FCC and band ratio provide simple and most effective analysis of variation of spectral signature recorded in each spectral bands of multispectral data and these data can be reproducible and easy to interpret. The interpreted lithological information of ASTER VNIR-SWIR bands are compared with the information extracted from the analysis of ASTER thermal bands. Further, ASTER visible-near-infrared(VNIR) and shortwave infrared (SWIR) bands are used to derive broad band albedo image to utilise it as complementary information while analysing the emissivity images derived from ASTER TIR channels. Understanding of albedo variations and variations in radiant temperatures of different terrain element are important to understand the spatial variations in emissivity amongst these elements In our study, radiant temperature image derived as by product of emissivity normalisation method has been taken as reference to understand the role of temperature in spectral radiance of each band.

In order to analyse ASTER level 1B thermal bands, we have used geological map prepared from conjugate consultation of regional geological map of Geological Survey of India and 
Geological map of Hutti Schist Belt prepared by Geological Society of India as reference geological information to interpret satellite derived images on emissivity and reflectivity variations for delineating rock types. As present work is focussed to analyze the potential of ASTER thermal bands to delineate major rock types of the study area,we have compared composites of thermal radiances first before deriving emissivity and radiant temperature from radiance data. As emissivity information are correlative and minute influences of atmosphere may influence in delineating contrast in emissivity, atmospheric correction algorithm is used to calibrate the thermal bands before analysing the radiance composite of thermal bands. In present study, in-scene atmospheric correction method is applied to calibrate thermal bands. This algorithm assumes that the atmosphere is uniform over the data scene and a nearblackbody surface exists within the scene. The algorithm determines the wavelength that exhibits the maximum brightness temperature among the bands based on statistical analysis. This wavelength is then used as the reference wavelength. The pixel spectra that have their brightest temperature at this wavelength are considered as reference black body and used to calculate the atmospheric compensation. In this regard, the reference blackbody radiance values are plotted against the measured radiances for each wavelength,. The upwelling and transmission of atmosphere is calculated from slope of fitted line derived based on the comparison between actual radiance of these pixels and modelled radiance(i.e. black body radiance based on Planck's equation).After applying inscene atmospheric correction in the data, we also have attempted masking of vegetation using third and second band of ASTER data. Vegetations are developed along lineaments and drianages; which have been masked based on derivation of normalised difference vegetation index(NDVI) from near infrared(band 3) and red( band ) of ASTER sensor.We also have derived albedo image using reflectance information of SWIR and VNIR bands of ASTER data to understand how albedo and radiant temperature have contributed in spectral radiances of thermal bands(Son et al., 2014).

As our main aim was to derive emissivity for each thermal band and using them as basis for geological information extraction; emissivity have been derived for each band using three different algorithms and their similarity and contrast are also examined. Emissivity derivation using $\mathrm{N}$ band thermal radiance data is under determined solutions as thermal radiance is governed by two parameters known as emissivity and temperature. If radiances are measured for $\mathrm{N}$ bands, there would be $\mathrm{N}+1$ unknowns. In this case, $\mathrm{N}$ would be emissivities at each wavelength and surface temperature would be another unknown variable. In this case, emissivity derivation problem using five thermal radiance bands has six unknown; five emissivity for five bands and radiant temperature. But we have five equations to derive such parameters. Therefore, assumptions are to be made in emissivity value to separate emissivity and temperature. In this regard, we have applied three emissivity extraction algorithms. In one method, a fixed emissivity (i.e., 0.96) is assumed to derive radiant temperature for each band. The emissivity to be assigned to the channel is 0.96 , which is acceptable approximation of emissivity values of geological materials. The highest temperature derived for each pixels from such set of radiant temperature images are used to derive emissivity for each pixels of each band using Plancks' equation. This method is known as emissivity normalisation method. In another method, emissivity of one thermal band is assumed constant to extract the radiant temperature of each band; which are subsequently used to derive emissivity information. This method is known as reference channel emissivity method
In third method, a parameter known as alpha residual is derived for each thermal bands. Alpha residuals are derived based on the linear approximation of Planck's equation based on Wien's approximation and this approximation is having $1 \% 2 \%$ bias for temperature(Lia et al., 2013). It has been observed that alpha residual spectra represents the shape of emissivity spectra well but it is not truly represent emissivity shape in higher wavelengths(Lia et al., 2013).

Emissivity composites of different bands are used to delineate major rock types of the study area. Further, we also have derived FCC images by applying decorrelational stretching on emissivity bands derived after removing noise using minimum noise fraction(MNF) method. It has been observed that emissivity bands are correlative in terms of information and characterised with low signal to noise ratio. Low SNR in ASTER thermal bands are evident from the striping noise of the emissivity composites(Fig.7). MNF method helps in segregating noise in data and also helps in arranging data as per the decreasing order of information content. In fact, MNF method is two cascaded principal component method in which noise whitened principal components are derived. Higher order MNF contain noise; which are removed while inversing emissivity information from MNF data space to original emissivity data space. In MNF method, noise are derived using shift difference algorithm operative over an area in the image; which appears homogeneous in terms of thermal radiance variation. In the study.Inverse-MNF Emissivity image has been used to analyse the signature of different rock types. Index images are also derived using emissivity bands derived using emissivity normalization method. Based on the analysis of emissivity composites; different rock types are delineated and imagederived emissivity spectra of two different granitoids are evaluated to see how emissivity spectra of these rocks behave in comparison to each other. We also have derived different false colour composites and band ratio composites from relative reflectance images of SWIR band to delineate main greenstone rocks and associated granitoids and analysis of these composite with respect to emissivity based image composites has also been attempted. A schematic flow diagram is given to illustrate the outline of methods followed for processing of the data(Figure 4). Results of the analysis of aforesaid images are discussed in the following segments

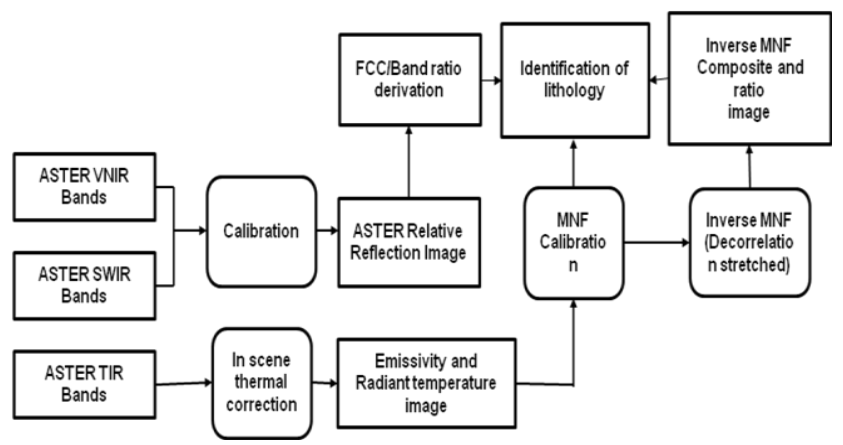

Figure 4: Generalised flow chart adopted for ASTER data analysis and processing

\section{RESULTS}

We have processed thermal data for delineating different rock types based on the variation in thermal properties (i.e. emissivity) and its associated surface cover elements. Thermal parameters of the rocks are not only governed by their chemical composition but also influenced by the soil,vegeration cover developed above these rocks. In tropical environmental set up, 
granitic rocks are also exposed to weathering and granitic saprolites are developed. Therefore, the presence of the exposures of granodiorite and granites are also scanty and the rocks are covered with arenaceous soil. On the other hand, metabasalt is intensely weathered and montmorillonite rich black soil is developed over metabasalt(Roy and Barde, 1962). In the study area, almost entire extent of metabasalt are covered with black soil except in few places. Metabasalt exposures are only restricted in the few isolated hills and also found along geological sections developed along nala(i.e. drainage section) and road. While analysing false colour composite of radiance image ( prepared using band 14 and 12 and 11)(Fig.5); we could delineate silica and K-feldspar rich granite(GN) based on its bright red colour in radiance composite image as quartz and $\mathrm{K}-$ Feldspar both have absorption in emissivity feature in band 12 and band 11( i.e. 2nd and 3rd thermal bands of ASTER)(Fig.5). Granodiorite(GR) is dark red as it lacks $\mathrm{K}$ Feldspar and also low in silica content in comparision to granite.Further mafic mineral content of this rock is relatively higher than granite. This reduces the spectral contrast of granodiorite in this emissivity bands and results dark red colour in the composite. Older granodiorite gneiss is regarded as distinct unit in comparison to younger alkali rich granites as albedo of granodiorite is high and slightly higher at places but broadly similar to the albedo of younger granite( which has good exposures reflecting incident energy well) as exposures of these rocks are massive and rich in high albedo bearing Calcium rich feldspar with low radiant temperature( please refer enlarged chips in the figure 5 where contrast in colour in radiance image is shown with contrast in albedo and radiant temperature image).In day time data; radiant temperature of granodiorite is very loe; even slightly lower than granite.

Black soil(BS),amphibolite(AMP) and basalt(MBL) are indistinguishable with their bright green colour in the radiance composites. These elements are all characterised with low albedo and high radiant temperate(Fig.5).However reddish tint observed below low albedo and high temperature bearing black soil( at the south-east part of the study area (Fig. 5.a) indicate the presence silica rich rock underneath(soil is developed above granodiorite at the south-east part of the study area).This indicates that the transported nature of this soil. On the other hand, black soil developed above metabasalt is in-situ soil and therefore the soil character is directly correlated with the metabasalt in terms of composition although soil is affected by pedological activity. Metabasalt and black soil have been grouped as single unit in terms of thermal character as thermal radiant temperature of these units are high and albedo of the units are low. Silica rich soil(SS) is also developed above granodiorite with high albedo and low radiant temperature at the south eastern part of the image. The soil has bright reflectance and rich in silica; which has been confirmed from analysis of SWIR bands. Conjugate analysis of albedo, radiance and radiant temperature images provide basis for characterisation of surface elements( rocks and soils)(Yajima and Yamaguchi, 2013).However, thermal bands are highly correlative in terms of information content(Table-2).

We have also made emissivity composite images from the emissivity bands derived using different emissivity extraction algorithms(Lia et al., 2013; Payan and Royer, 2004). However; these emissivity images provide low contrast information(even if after applying decorrelational stretching on these composite images)(Fig.6) and striping noises are evident in these emissivity composites(Son et al., 2014). Silica rich younger granite is having intense red colour in these composites(Fig.6.a.b and c).Emissivity composite derived using emissivity normalization method provides better contrast than the composites derived using reference channel and alpha residual method(Fig.6).However, Signal to noise ratio of thermal emissivity bands derived using each algorithm are also low. This has been estimated based on derivation Minimum Noise Fraction (MNF) image; which can segregate signal from noise using two cascaded principal component method; which separate higher order noise rich MNF bands from lower order signal rich MNF bands(Fig. 7). The concept and potential of MNF method in segregating signal for image analysis is well discussed in literature(Rowan et al., 2005; Zhang et al., 2007). It has been observed that emissivity bands derived using three different algorithms have comparable signal and noise content. This has been observed based on both visual analysis of MNF bands and also deriving plot of Eigen value and Eigen number(MNF band number)(Fig.7). It has been observed that information have been reduced after MNF band 3 and two higher order MNF bands are dominated with noise. As emissivity normalised image provides better contrast of colur required to delineate rocks in comparison to reference channel method and alpha residual method; emissivity bands derived using this method are subjected to inverse analysis based on using first three MNF bands for inverse operation. Inverse MNF composite image thus derived have been decorrelation stretched to delineate rock types and associated surface elements(Fig.8.a).We could delineate granite from granodiorite based on contrasting colours and amphibolite appear with blue colour in this composite image and this helps in separating amphibolite exposures from basalt. Presence of granophyres within green schist rocks are also enhanced( shown with ellipse in Fig.8.a).Emissivity spectra of Quartz, Feldspars and different mafic minerals are shown in Fig. 8.b. Based on the analysis of image spectra of amphibolite, granite and granodiorite ratio images are derived.These ratios are band 14/band 12 and band 10/band 12. Emissivity spectra are derived from visible exposures of these rocks and compared with the ASTER convolved laboratory spectra(Fig.9.b).

These ratios are coined to enhance the contrast between granite and granodiorite as granodiorite has emissivity spectra with shallower depth than granite. Amphibolite is featureless with gradual fall in emissivity is observed at the higher bands(Fig. 9.b).Based on the contrast in image derived emissivity spectra of aforesaid rocks; the ratio images were derived. These ratio images are further used to derive composite images to delineate different rock types(Fig.9.a).Although this composite could delineate granite(yellow in colour) and granodiorite(green in colour) but it could not delineate basalt and amphibolite.

We also have derived false colour composites using calibrated SWIR bands and the ratio images are also derived from these bands. We have used index images known for delineating mafic rocks from granite and also known for its potential for delineating chlorite rich rock( in this case metabasalt) and amphibole rich rock( in this case amphibolite).These ratio images are further used in derivation of false colour composites for delineating different rock types. It has been observed that the ratio composites and simple composites could delineate 
amphibolite from metabasalt. Moreover; granite and granodiorites are also well delineated in SWIR band derived ratio images as these rocks have different mafic minerals; known for their spectral absorption feature in the SWIR bands of ASTER sensor.

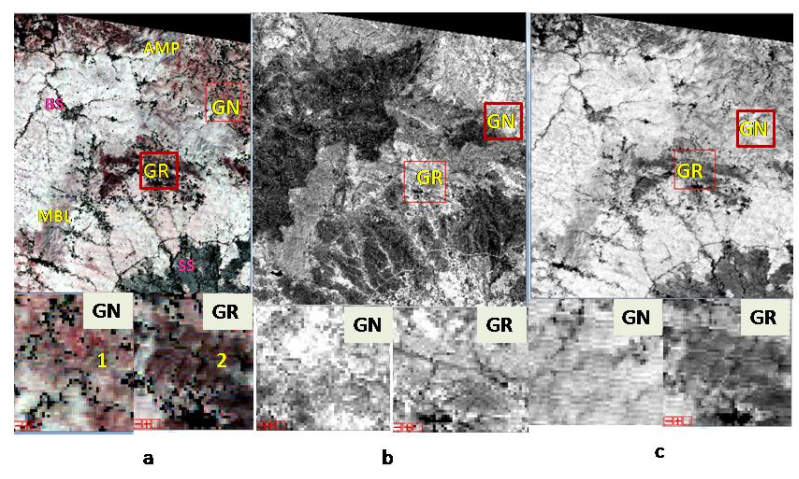

Figure 5 a. False colour radiance composite image ( Red= Band 14, Green= Band 12 and Blue=Band 11) b. ASTER VNIR-SWIR derived albedo image((Yajima and Yamaguchi, 2013).C. Radiant temperature image derived using emissivity normalisation method.

In the image, $\mathrm{MP}=\mathrm{Amphibolite}, \mathrm{BS}=\mathrm{Black}$ -

soil, $\mathrm{GN}=$ Granite, $\mathrm{GR}=$ Granodiorite,

$\mathrm{MP}=$ Amphibolite, $\mathrm{MBL}=$ metabasalt, $\mathrm{SS}$ :Silica rich soil. In the zoomed portion of the figure $1=$ granite exposure, $2=$ Granodiorite

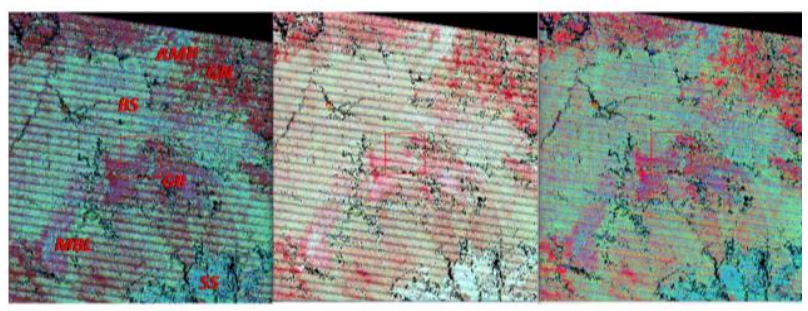

Figure 6 a. False colour composite of emissivity bands derived using emissivity normalisation method b. False colour composite of emissivity bands derived using reference channel method c. False colour composite of emissivity bands derived using alpha residual method. Strping noise is evident in this composite images.In this composite Red=Band 14, Green $=$ Band12 and Blue $=$ Band 11. Labelling has same nomencalture as shown in Figure 1.

\begin{tabular}{|c|c|c|c|c|c|}
\hline Correlation & $\begin{array}{c}\text { Band } \\
\mathbf{1 0}\end{array}$ & Band11 & Band12 & $\begin{array}{c}\text { Band } \\
\mathbf{1 3}\end{array}$ & $\begin{array}{c}\text { Band } \\
\mathbf{1 4}\end{array}$ \\
\hline Band 10 & 1.000 & 0.998 & 0.998 & 0.997 & 0.997 \\
\hline Band 11 & 0.9982 & 1.000 & 0.999 & 0.998 & 0.997 \\
\hline Band 12 & 0.998 & 0.9991 & 1.000 & 0.998 & 0.997 \\
\hline Band 13 & 0.997 & 0.9985 & 0.998 & 1.000 & 0.999 \\
\hline Band14 & 0.9970 & 0.997 & 0.997 & 0.999 & 1.000 \\
\hline
\end{tabular}

Table 2 : Correlation matrix of ASTER thermal radiance band

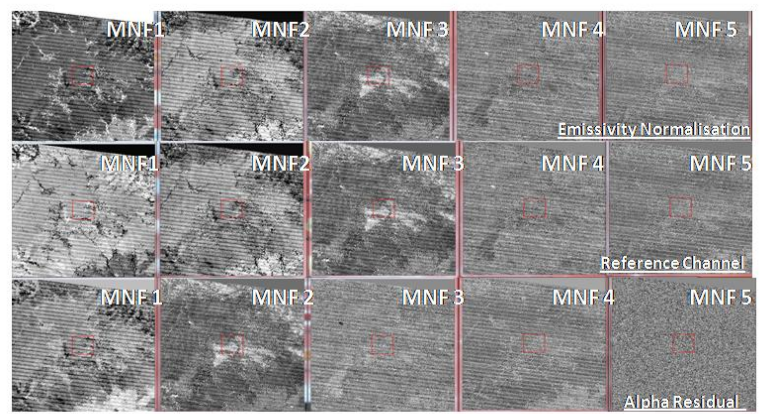

$\mathbf{a}$

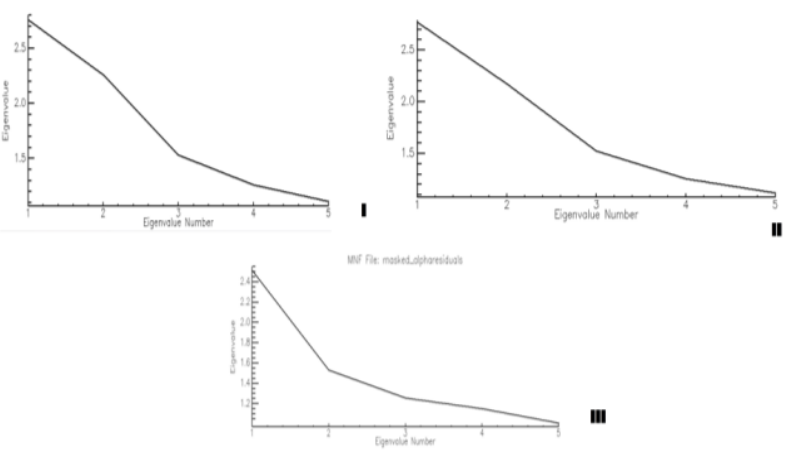

Figure 7: a. MNF bands derived from emissivity bands derived using emissivity normalisation(I), reference channel(II) and alpha residual(III) method. b. Graphical plot of Eigen value and band number to show how information content reduces after three MNF bands. ( the graph is not clear)

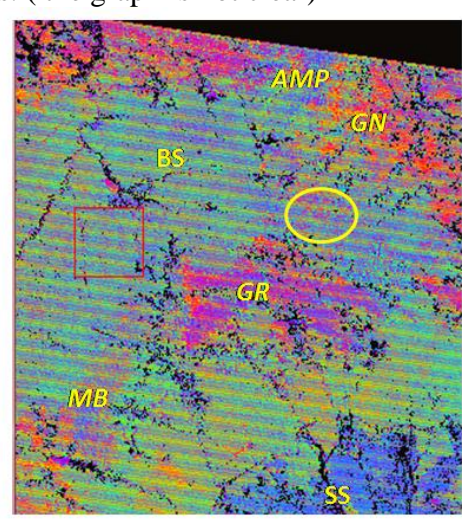

$\mathbf{a}$

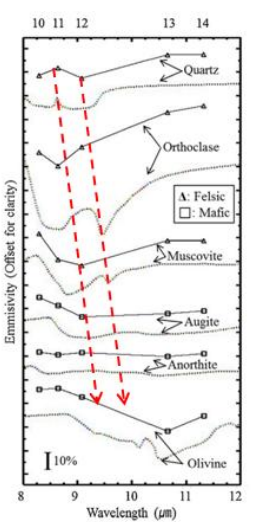

b
Figure 8: a. Inverse MNF image Composite derived from signal dominated emissivity bands derived using emissivity normalised method. In the composite $(\mathrm{Red}=$ Band 14 , Green=Band 12 and Blue=Band 11).b. ASTER derived Emissivity spectra of different rock forming minerals are shown to illustrate orthoclase has absorption at band 11 and quartz has 
aborption at band 12(Son et al., 2014). Labelling has same nomencalture as shown in Figure 1.

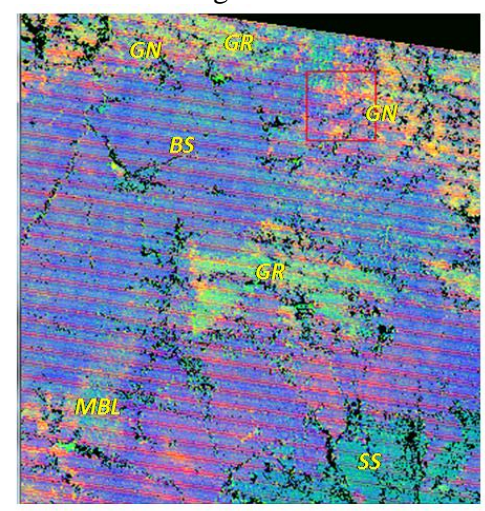

a

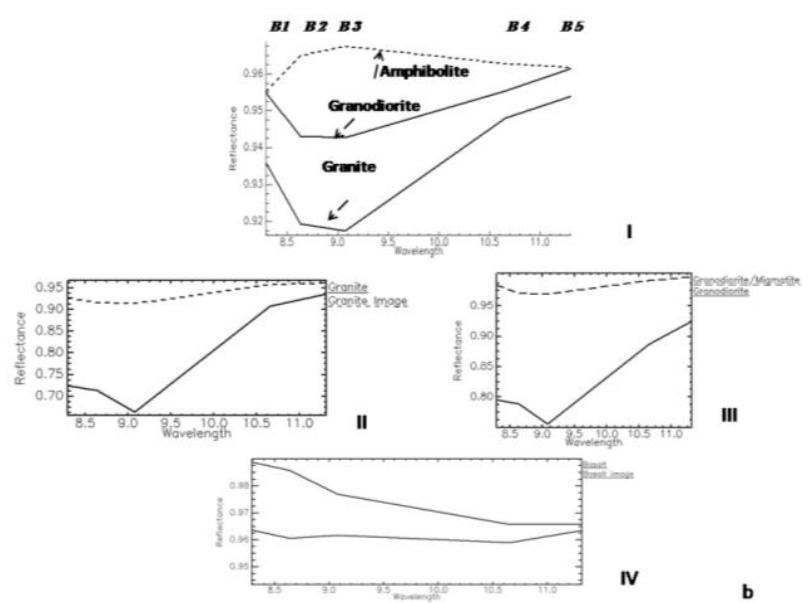

Figure 9 a. Composite of two ratio image derived from emissivity bands derived using emissivity normalisation method and emissivity band 12 .Raio images are derived using band 14/band 12(ratio 1), band 12 and band 10(ratio 2).In FCC, Red $=$ Ratio1, Green $=$ Ratio2, Blue $=$ Band 12. b. ASTER image derived emissivity spectra of three major rocks(I) and image derived emissivity spectra of each rock is compared with laboratory emissivity spectra of rocks( after convolving to ASTER bandwidth) collected from John Hopkins University(JHU) library( labelled as II,III and IV respectively).

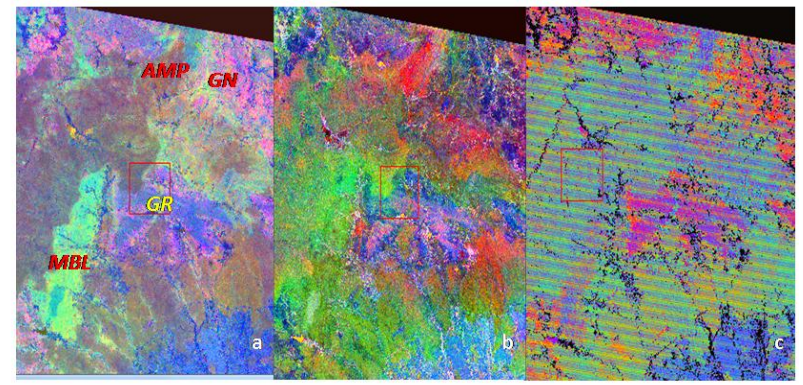

Figure 10 a. False colour composite of ASTER SWIR bands where Red $=$ Band 5, Green $=$ Band 6 and Blue $=$ Band 8 . b.ASTER band ratio composite where Red $=(6+9) /(7+8)$; ratio is good for delineating amphibole,Green $=5 / 8$; ratio is for chlorite and Blue $=4 / 5$ for granite. $C$.ASTER Inverse MNF composite is also shown to analyse the potential of TIR bands and SWIR bands in delineating geology as shown in Figure 6. Labelling has same nomencalture as shown in Figure 1.

\section{CONCLUSIONS}

Emissivity information derived from processing of ASTER data are highly correlated. Emissivity composites derived using different algorithms provide comparable results, however, emissivity normalisation method provide slightly better contrast required to delineate different rock types and associated terrain elements in comparison to emissivity composite derived using reference channel and alpha residual method. Multiband emissivity derived using different emissivity extraction methods are highly correlated. Therefore MNF bands are derived to identify the information and noise content in the data and decorrelation stretching of inverse MNF composite has been utilised to identify the different rock types and associated terrain elements. ASTER thermal band derived image spectra are also used to delineate major rock types based on derivation of ratio images and its composite. But thermal bands of ASTER could only delineate granite and granodiorites. It also could delineate the granodiorite even if it is covered with black soil. Presence of soil cover and similar albedo, radiant temperature of soil blanketing metabasalt prohibits emissivity based delineation of metabasalt. Amphibolite also feature-less in multiband emissivity data as it has broad spectra with very gradual fall in emissivity in the high wavelength bearing thermal bands. From the results obtained from analysis of emissivity composites derived from ASTER thermal band, it is observed that these data are suitable for delineating granitoids having different silica content. But delineation of metabasalt and amphibolite is better in ASTER SWIR band and ratio composites. Moreover; granites of different silica content are also delineated in SWIR bands based on the variations in mafic mineral contents in these granites as these minerals have their diagnostic absorption feature ASTER SWIR bands.

\section{ACKNOWLEDGEMENTS}

Authors are grateful to Director,NRSC and Deputy Director,Remote Sensing Application Area,NRSC for their guidance and encouragement for the work.

\section{REFERENCES}

Abrams, M., 2000., The Advanced Spaceborne Thermal Emission and Reflection Radiometer (ASTER): data products for the high spatial resolution imager on NASA's Terra platform. International Journal of Remote Sensing 21 (5), pp 847-859.

Abrams, M.J., Kahle, A.B., Palluconi, F.D., Schieldge, J.P., 1984. Geologic mapping using thermal images. Remote Sensing Environment, 16, pp 13-33.

Bertoldi, L., Massironi, M., VisonÃ, D., Carosi, R., Montomoli, C., Gubert, F., Naletto, G., Pelizzo, M.G., 2011., Mapping the Buraburi granite in the Himalaya of Western Nepal: Remote sensing analysis in a collisional belt with vegetation cover and extreme variation of topography. Remote Sensing of Environment, 115, pp 1129-1144.

Curtis, I.C., RadhaKrishna, B.P., 1995., Hutti Gold Mine(Into the 21 st Century). Geological Society of India.

Ding, C., Liu, X., Liu, W., Liu, M., Li, Y., 2014.Mafic and ultramafic and quartz-rich rock indices deduced from ASTER thermal infrared data using a linear approximation to the Planck function. Ore Geology Reviews, 60, pp 161-173. 
Gillespie, A.R., 1992. Enhancement of multispectral thermal infrared images: Decorrelation contrast stretching. Remote Sensing of Environment, 42, pp 147-155.

Guha, A., Singh, V.K., Parveen, R., Vinod Kumar, K., Jeyaseelan, A.T., Dhanamjaya Rao, E.N., 2013. Analysis of ASTER Data for Mapping Bauxite Rich Pockets within High Altitude Lateritic Bauxite, Jharkhand, India. International Journal of Applied Earth Observation and Geoinformation,21, pp 184-194.

Hulley, G.C.H., Simon J. , 2009. The North American ASTER Land Surface Emissivity Database (NAALSED)

Version 2.0. Remote Sensing of Environment, 113, 1967-1975.

Kahle, A.B., Rowan, L.C., 1980. Evaluation of multispectral middle infrared aircraft images for lithologic mapping in the East Tintic Mountains, Utah. Geology, 8, pp 234-239.

Kalinowski, A., Oliver, S.A., 2004. ASTER Mineral Index Processing Manual

(http://www.ga.gov.au/image_cache/GA7833.pdf)

Lia, Z.-L., Wua, H., Wanga, N., Qiub, S., Sobrinod , J.A., Wane, Z., Tanga , B.-H., Yanf, G., 2013. Land surface emissivity retrieval from satellite data. International Journal of Remote Sensing, 34, pp 3084-3127.

Lyon, R.J.P., 1972. Infrared spectral emittance in geological mapping: airborne spectrometer data from Pisgah Crater. Science, 7, pp 983-986.

Matar, S.S., Bamousa, A.O., 2013. Integration of the ASTER thermal infra-red bands imageries with geological map of Jabal Al Hasir area, Asir Terrane, the Arabian Shield. Journal of Taibah University for Science, 7, pp 1-7.

Ninomiya, Y., Fu, B., Cudahy, T.J., 2005. Detecting lithology with Advanced Spaceborne Thermal Emission and Reflection Radiometer (ASTER) multispectral thermal infrared â€œradiance-at-sensorâ€• data. Remote Sensing of Environment, 99, pp 127-139.

Ninomiya, Y., Matsunaga, T. , Yamaguchi, Y., Ogawa, K., Rokugawa, S., Uchida, K., Muraoka, H., Kaku, M., 1997. A comparison of thermal infrared emissivity spectra measured in situ, in the laboratory, and derived from thermal infrared multispectral scanner (TIMS) data in Cuprite,Nevada, U.S.A. International Journal of Remote Sensing, 18, pp 1571-1581.

Norman, J.M., \& Becker, F.,1995. Terminology in thermal infrared remote-sensing of natural surfaces. Agricultural and Forest Meteorology 77, pp 153-166.

Payan, V., Royer, A., 2004. Analysis of Temperature Emissivity Separation (TES) algorithm applicability and sensitivity. International Journal of Remote Sensing, 25, pp 15-37.

Rowan, L.C., Mars, J.C., Simpson, C.J., 2005. Lithologic mapping of the Mordor, NT, Australia ultramafic complex by using the Advanced Spaceborne Thermal Emission and Reflection Radiometer (ASTER). Remote Sensing of Environment,99, pp 105-126.

Roy, A., 1979. Polyphase folding deformation in the HuttiMaski schist belt, Karnataka. Jounal of Geological Society of India, 20, 598-607.

Roy, B.B., Barde, N.K., 1962. Some characterisation of black soils in India. Soil science 93, pp 142-147.

Son, Y.-S., Kang, M.-K., Yoon, W.-J., 2014. Lithological and mineralogical survey of the Oyu Tolgoi region, Southeastern Gobi, Mongolia using ASTER reflectance and emissivity data. International Journal of Applied Earth Observation and Geoinformation, 26, pp 205-216.

Yajima, T., Yamaguchi, Y., 2013. Geological mapping of the Francistown area in northeastern Botswana by surface temperature and spectral emissivity information derived from Advanced Spaceborne Thermal Emission and Reflection
Radiometer (ASTER) thermal infrared data. Ore Geology Reviews, 53, pp 134-144.

Zhang, X., Pazner, M., Duke, N., 2007. Lithologic and mineral information extraction for gold exploration using ASTER data in the south Chocolate Mountains (California). ISPRS Journal of Photogrammetry and Remote Sensing 62, pp 271-282. 